\title{
O DIREITO DE PROPRIEDADE E A SUPREMACIA DO INTERESSE PÚBLICO SOBRE O PRIVADO NA ERA DE ADAPTAÇÃO ÀS MUDANÇAS CLIMÁTICAS
}

\author{
Fernanda Dalla Libera Damacena \\ Mestre em Direito Público pela Universidade do Vale do \\ Rio dos Sinos (Capes 6). Especialista em Direito do Estado \\ pela UFRGS. Bacharel em Direito pela Unisinos. \\ Professora da Escola de Direito - Unisinos. Doutoranda em \\ Direito. Advogada. \\ fdamacena@unisinos.br

\begin{abstract}
Suelen Webber
Doutora e Mestre em Direito Público pela Universidade do Vale do Rio dos Sinos (Capes 6). Bacharel em Direito pela Universidade de Caxias do Sul. Advogada. Pesquisadora e Parecerista. suelenwebber@terra.com.br
\end{abstract}

\begin{abstract}
RESUMO: Tendo em vista as já detectadas e prováveis consequências das alterações climáticas sobre bens e serviços, observa-se o crescimento de uma postura de conservação, sobretudo, ecossistêmica, o que sinaliza para a necessidade de evolução adaptativa de diversos direitos, entre eles o de propriedade. A partir dessa perspectiva, o presente artigo analisou a evolução da tensão histórica entre o direito de propriedade e o direito ambiental brasileiro, cuja progressão segue em curso e deve ser evidenciada pela necessidade de adaptação à mudança climática. Um dos argumentos mais evidentes nesse processo é o princípio da supremacia do interesse público sobre o privado, tanto no âmbito doutrinário, quanto jurisprudencial. Com vistas a fomentar o debates sobre essa questão, o artigo colacionou uma compilação de argumentos favoráveis e contrários a atual compreensão do princípio, recorrentemente enunciado quando o objetivo é o empenho de maior atenção aos objetivos da tutela ambiental num contexto de função social da propriedade. Ao se valer de raciocínio hipotético-dedutivo, por meio de pesquisa bibliográfica e jurisprudencial, descritiva e exploratória, observa-se que diante de um cenário científico que orienta uma abordagem adaptativa, as ingerências - legais, administrativas e judiciais no direito de propriedade devem aumentar. Contudo, tais medidas devem vislumbrar o interesse público, a partir de decisões que procurem harmonizar a necessária tutela de um ambiente ecologicamente equilibrado, com o direito de propriedade, o que remete à segurança patrimonial e jurídica, nos termos estabelecidos pelo Estado Democrático de Direito.
\end{abstract}

PALAVRAS-CHAVE: Mudança climática; Direito Ambiental; Direito de propriedade; Adaptação; Supremacia interesse público sobre o privado. 
O direito de propriedade e a supremacia do interesse público sobre o privado na era de adaptação às mudanças climáticas

The property right and the supremacy of public interest over private in the age of climate change adaptation

ABSTRACT: Bearing in mind the already detected and likely consequences of climate change on goods and services, we can observe the growth of a conservation posture, above all ecosystems, which indicates the need for adaptive evolution of several rights, including property rights. From this perspective, the present article analyzed the evolution of the historical tension between the right of ownership and the Brazilian environmental law, whose progression is still ongoing and must be evidenced by the need to adapt to climate change. One of the most evident arguments in this process is the principle of the supremacy of the public interest over the private, in doctrinal as well as jurisprudential. In order to stimulate debate on this issue, the article has put together a collection of arguments that are favorable and contrary to the current understanding of the principle, which is repeatedly stated when the objective is to focus more attention on the objectives of environmental protection in a context of the social function of property. By using hypothetical-deductive, reasoning, through a descriptive and exploratory bibliographic and jurisprudential research it was observed that, in the face of a scientific scenario that guides an adaptive approach, interference - legal, administrative and judicial in property law must increase. However, such measures should serve the public interest, giving priority to decisions that harmonize the necessary protection of an ecologically balanced environment, without disregarding property rights, property and legal security, according to the rule of law.

KEYWORDS: Climate change; Environmental Law; Property right; Adaptation; Supremacy public interest over private.

\section{INTRODUÇÃO}

Como preservar e recuperar recursos finitos à luz das novas necessidades e conflituosidades sociais é uma das perguntas mais desafiadoras já direcionadas ao Direito e à sociedade. Sob a perspectiva do direito ambiental, a questão pode ser observada pela análise da conhecida tensão entre o direito de propriedade e tutela do ambiente.

Instrumentalmente, a legislação é ferramenta importante para criar, definir atribuições, gerenciar e proteger o direto de propriedade. Essa mesma lei, por orientação constitucional, estabelece regras para que seu uso respeite bens e serviços ambientais. Atualmente, a dicção constitucional tem sido compreendida como uma orientação de uso sustentável da terra, com vistas à tutela de um bem que é de uso comum do povo.

Em um cenário de adaptação às mudanças climáticas, a ingerência legal, administrativa e judicial sobre o direito de propriedade tende a aumentar. Dessa possiblidade exsurgem uma série de questões como, por exemplo, quais os limites, possibilidades e critérios de fundamentação.

A tensão entre direito de propriedade e meio ambiente é antiga, contudo, poucos assuntos são tão atuais e regulados pelo Direito brasileiro. Devido às necessárias adaptações aos efeitos da mudança climática prenunciados pela ciência, essa relação pode se tornar ainda mais complexa. Diante dessa realidade, uma das maiores preocupações passa a ser como adaptar o direito de propriedade sem exauri-lo.

A leitura do direito de propriedade realizada por boa parte do Direito brasileiro na atualidade é explicada por razões científicas e históricas, apontadas como justificativas para a incisiva regulamentação deste direito fundamental na atualidade. Dois critérios de fundamentação, por vezes complementares, bastante utilizados pela doutrina e jurisprudência, balizam a possibilidade de restrição ao direito de propriedade. O primeiro ancora-se na tese de que ao lado dos 
direitos fundamentais existem deveres fundamentais de solidariedade. O segundo, diz respeito à supremacia do interesse púbico sobre o privado.

Contudo, se por um lado é verdade que até por uma questão de necessidade a propriedade é um dos vários direitos a ter de se adaptar a uma nova realidade, por outro, a adaptação das regras relativas ao esse direito será, provavelmente, mais desafiadora e complexa do que em outros contextos e ramos do Direito. Ou seja, ainda que a mudança climática deva reajustar significativamente os direitos de propriedade, essa evolução não será fácil. "A propriedade tem a capacidade de criar vínculos econômicos e emocionais, difíceis de serem modificados". Isso sem falar na complexidade das "situações consumadas" (DOREMUS, 2012, p. 1092), e na tradicional valorização da estabilidade. Todas essas características chocam-se frontalmente com a necessidade de agilidade de adaptação diante das transformações causadas pelos efeitos já observados e, também, futuros das mudanças climáticas.

A partir das questões anteriormente pontuadas, o presente artigo analisou a evolução da tensão histórica entre o direito de propriedade e o direito ambiental brasileiro, cuja progressão segue em curso e deve ser evidenciada pela prenunciada necessidade de adaptação à mudança climática. Esse processo de adaptação tem gerado maiores restrições ao direito de propriedade. Um dos argumentos utilizados nesse contexto é o princípio da supremacia do interesse público sobre o privado, o que já demanda uma necessária revisão da literatura. Com vistas a elucidar essa revisão, colacionou-se uma compilação de argumentos diversos no que concerne ao emprego do princípio que é comumente mencionado quando o objetivo é o empenho de maior atenção aos objetivos da tutela ambiental num contexto de função social da propriedade.

$\mathrm{O}$ artigo foi estruturado em três tópicos. O primeiro aborda a evolução normativa, constitucional e hermenêutica da tensa relação entre a tutela ambiental e o direito de propriedade, até os dias atuais. O segundo, por sua vez, evidencia os prognósticos do cenário científico das mudanças climáticas, seu impacto no direito de propriedade, e as dificuldades típicas desse processo de adaptação. O terceiro, apresenta reflexões doutrinárias favoráveis, contrárias e intermediárias no que concerne à compreensão do argumento de supremacia do interesse público sobre o privado e sua aplicação ao direito de propriedade num contexto de adaptação às mudanças do clima. A pesquisa desenvolveu-se a partir de um raciocínio hipotético-dedutivo, por meio de pesquisa bibliográfica e jurisprudencial, descritiva e exploratória.

\section{A TUtela AMbiental E O DIREITO DE PROPRIEDADE}

Se as tensões entre a proteção do meio ambiente e o direito de propriedade já eram conhecidas, a adaptação aos impactos das mudanças climáticas implicará litigâncias altamente complexas. Atualmente, uma das questões mais debatidas nesse âmbito, reforça a interface entre o público e o privado, representada, no direito ambiental brasileiro, pela função social da propriedade.

Historicamente o ser humano interagiu e contribuiu para a alteração dos ecossistemas no planeta. Com a organização de indivíduos e famílias em comunidades e sociedades, o potencial humano de modificação do meio aumentou. A especialização do trabalho e o constante desenvolvimento de tecnologias propiciaram a capacidade de mudar floresta em pastagem, deserto em terras agrícolas, em grande escala e ritmo. Não por outra razão, constituições, legislações e regras administrativas passaram a regular as interações humanas com o ambiente. Uma das interações mais conhecidas entre ambiente e homem se dá pelo exercício do direito de propriedade. A relação ambiente e propriedade sofreu uma metamorfose ao longo de décadas e é, atualmente, uma das mais regulamentadas no Brasil. 
O direito de propriedade e a supremacia do interesse público sobre o privado na era de adaptação às mudanças climáticas

No Direito brasileiro a propriedade privada partiu de uma concepção individualista que, progressivamente, foi flexibilizada e limitada. Da garantia do direito de propriedade em sua quase plenitude, consagrada nas constituições de 1824, 1891 e 1934, passou-se, nas constituições de 1946 e de 1967, à ressalva de o direito não poder ser exercido contra interesse social ou coletivo. A Constituição de 1988, no artigo $5^{\circ}$, garante o direito fundamental de propriedade (inc. XXII) mas, o mesmo tempo, apregoa que ela deve atender à função social (inc. XXIII) (FREITAS, 2008, p.114-118). A mesma perspectiva em relação ao exercício da propriedade pode ser observada pela leitura menos patrimonialista, individualista, mais coletiva e inclusiva do Código Civil de 2002. ${ }^{1}$

Pelo fato de envolver diversos ramos do direito, a propriedade inter-relaciona institutos e, ao mesmo tempo, é altamente limitada por eles. No direito constitucional observa-se essa restrição pelos contornos da função social, fortemente interligados com a tutela do meio ambiente. No âmbito administrativo, pelas questões envolvendo tombamento, zoneamento, servidão administrativa, direito de construir, desapropriação. No direito civil, pelo usufruto, condicionantes de testamento, reconhecimento da função socioambiental, entre outros.

Contudo, o direito ambiental tem sido, nos últimos anos, tanto do ponto de vista legislativo quanto jurisdicional, o ramo que mais tem influenciado a releitura do direito de propriedade, a partir de uma perspectiva difusa, de valorização da equidade (WEISS, 1990) intergeracional e da sustentabilidade. (FREITAS, 2011; FERRER et al, 2014). Nesse sentido, a função social é vista como princípio de controle do exercício do direito de propriedade.

Conforme salienta Eros Grau (2004, p. 222), “impõe ao proprietário - ou a quem detém o poder de controle - o dever de exercê-lo em benefício de outrem e não, apenas, de não o exercer em prejuízo de outrem”. Percebe-se, assim, que a função social da propriedade atua como fonte da imposição de comportamentos positivos ao detentor do poder que deflui da propriedade, de prestação de fazer, e não, meramente, de não fazer.

Um dos principais interpretes da relação ente o exercício do direito de propriedade e sua função socioambiental tem sido o Superior Tribunal de Justiça, que inclusive já relacionou a necessidade de preservação de áreas especialmente protegias, com vistas à adaptação às mudanças climáticas. A ementa do REsp 650728 / SC ${ }^{2}$ representa bem essa situação.

A legislação brasileira atual reflete a transformação científica, ética, política e jurí-
dica que reposicionou os manguezais, levando-os da condição de risco à saúde pú-
blica ao patamar de ecossistema criticamente ameaçado. Objetivando resguardar suas
funções ecológicas, econômicas e sociais, o legislador atribuiu-lhes o regime jurídico
de Área de Preservação Permanente. É dever de todos, proprietários ou não, zelar
pela preservação dos manguezais, necessidade cada vez maior, sobretudo em época
de mudanças climáticas e aumento do nível do mar. Destruí-los para uso econômico
direto, sob o permanente incentivo do lucro fácil e de benefícios de curto prazo,
drená-los ou aterrá-los para a especulação imobiliária ou exploração do solo, ou

1 Vide exemplo do artigo 1228, $\S 1^{\circ}$, Código Civil. "Art. 1.228. O proprietário tem a faculdade de usar, gozar e dispor da coisa, e o direito de reavê-la do poder de quem quer que injustamente a possua ou detenha.

$\S 1^{\circ} \mathrm{O}$ direito de propriedade deve ser exercido em consonância com as suas finalidades econômicas e sociais e de modo que sejam preservados, de conformidade com o estabelecido em lei especial, a flora, a fauna, as belezas naturais, o equilíbrio ecológico e o patrimônio histórico e artístico, bem como evitada a poluição do ar e das águas".

2 BRASIL. Superior Tribunal de Justiça. REsp 650728 / SC. Segunda Turma. Min. Herman Benjamin. DJe 02 dez. 2009. PROCESSUAL CIVIL E AMBIENTAL. NATUREZA JURÍDICA DOS MANGUEZAIS E MARISMAS. TERRENOS DE MARINHA. ÁREA DE PRESERVAÇÃO PERMANENTE. ATERRO ILEGAL DE LIXO. DANO AMBIENTAL. RESPONSABILIDADE CIVIL OBJETIVA. OBRIGAÇÃO PROPTER REM. NEXO DE CAUSALIDADE. AUSÊNCIA DE PREQUESTIONAMENTO. PAPEL DO JUIZ NA IMPLEMENTAÇÃO DA LEGISLAÇÃO AMBIENTAL. ATIVISMO JUDICIAL. MUDANÇAS CLIMÁTICAS. DESAFETAÇÃO OU DESCLASSIFICAÇÃO JURÍDICA TÁCITA. SÚMULA 282/STF. VIOLAÇÃO DO ART. 397 DO CPC NÃO CONFIGURADA. ART. 14, § $1^{\circ}$, DA LEI 6.938/1981. 
transformá-los em depósito de lixo caracterizam ofensa grave ao meio ambiente ecologicamente equilibrado e ao bem-estar da coletividade, comportamento que deve ser pronta e energicamente coibido e apenado pela Administração e pelo Judiciário. (grifo nosso)

Logo, em sendo o direito de propriedade e meio ambiente duas faces de uma mesma moeda, a tutela do segundo implica interferência no primeiro (BENJAMIN, 1996). O licenciamento ambiental, a nova lei florestal (Lei 12.651/12) e a Lei 9.985/00 (Sistema Nacional de Unidade de Conservação) são comumente mencionados como exemplos dessa influência no direito de propriedade, que varia entre a possibilidade de limitação (interferência) e a desapropriação (intervenção).

Nessa linha, mesmo que concebida como direito fundamental, a propriedade não é mais compreendida como um direito que se possa erigir à suprema condição de absoluto, ilimitado e inatingível. Esse entendimento ganhou tamanha proporção que passou a ser positivado pela Lei $12.651 / 12 .{ }^{3}$ Contudo, mesmo antes da normatização da obrigação propter rem como suporte fático, com base no princípio da função social da propriedade, parte da doutrina e jurisprudência ${ }^{4}$ já sustentava a possibilidade de imposição ao proprietário rural do dever de recomposição da vegetação em áreas de preservação permanente e reserva legal, mesmo não tendo sido ele o responsável pelo desmatamento, pelo fato de que a obrigação possuir caráter real. Isto é, uma obrigação que adere ao titular do direito real, seja ele quem for, bastando para tanto sua simples condição de proprietário ou possuidor (MILARÉ, 1998).

Nos termos da Constituição Federal, a função social é cumprida quando a propriedade rural atende, simultaneamente, segundo critérios e graus de exigência estabelecidos em lei e, entre outros requisitos: a utilização adequada dos recursos naturais disponíveis e preservação do meio ambiente. A previsão constitucional impõe ao proprietário um dever de proteção altamente relevante para a coletividade, especialmente em tempos de mudança climática. Ao poder público, para assegurar a efetividade desse direito, incumbe inúmeras ações previstas pelo artigo 225 , $\S$ $1^{\circ} \mathrm{e}$ incisos. Entre elas pode-se mencionar as que mais têm relação com o direito de propriedade:

I - preservar e restaurar os processos ecológicos essenciais e prover o manejo ecológico das espécies e ecossistemas;

II - preservar a diversidade e a integridade do patrimônio genético do País e fiscalizar as entidades dedicadas à pesquisa e manipulação de material genético;

III - definir, em todas as unidades da Federação, espaços territoriais e seus componentes a serem especialmente protegidos, sendo a alteração e a supressão permitidas somente através de lei, vedada qualquer utilização que comprometa a integridade dos atributos que justifiquem sua proteção; (Regulamento)

\footnotetext{
3 Art. $2^{\circ}$ As florestas existentes no território nacional e as demais formas de vegetação nativa, reconhecidas de utilidade às terras que revestem, são bens de interesse comum a todos os habitantes do País, exercendo-se os direitos de propriedade com as limitações que a legislação em geral e especialmente esta Lei estabelecem. § 2o As obrigações previstas nesta Lei têm natureza real e são transmitidas ao sucessor, de qualquer natureza, no caso de transferência de domínio ou posse do imóvel rural. BRASIL. Lei 12.608 de 25 de maio de 2012. Dispõe sobre a proteção da vegetação nativa; altera as Leis nos 6.938, de 31 de agosto de 1981, 9.393, de 19 de dezembro de 1996, e 11.428, de 22 de dezembro de 2006; revoga as Leis nos 4.771, de 15 de setembro de 1965, e 7.754, de 14 de abril de 1989, e a Medida Provisória no 2.166-67, de 24 de agosto de 2001; e dá outras providências.

${ }^{4}$ Nesse sentido, entendimento do Superior Tribunal de Justiça. A jurisprudência desta Corte está firmada no sentido de que os deveres associados às APPs e à Reserva Legal têm natureza de obrigação propter rem, isto é, aderem ao título de domínio ou posse, independente do fato de ter sido ou não o proprietário o autor da degradação ambiental. Casos em que não há falar em culpa ou nexo causal como determinantes do dever de recuperar a área de preservação permanente. Este Tribunal tem entendido que a obrigação de demarcar, averbar e restaurar a área de reserva legal nas propriedades rurais configura dever jurídico (obrigação ex lege) que se transfere automaticamente com a mudança do domínio, podendo, em consequência, ser imediatamente exigível do proprietário atual. BRASIL. AgRg no REsp 1367968 / SP. Segunda Turma, Rel. Humberto Martins, Dje: 12.03.2014.
} 
O direito de propriedade e a supremacia do interesse público sobre o privado na era de adaptação às mudanças climáticas

IV - exigir, na forma da lei, para instalação de obra ou atividade potencialmente causadora de significativa degradação do meio ambiente, estudo prévio de impacto ambiental, a que se dará publicidade.

As orientações constitucionais ganham força na medida em que a biodiversidade é prejudicada ou exposta a riscos. A desconsideração da ciência climática fomenta, negativamente, a desconsideração de medidas de preservação, mitigação e recuperação da biodiversidade e serviços ecossistêmicos existentes em propriedades. A preocupação com a perda de biodiversidade no mundo está justificada por representar uma das maiores crises da atualidade. Biodiversidade e alterações climáticas podem parecer problemas distantes, que se conectam somente por acaso. Engana-se quem aceita essa afirmação como verdadeira. "Biodiversidade e mudança climática são sistemas absolutamente interligados" (FARBER, 2015, p.2). As alterações climáticas têm impactado e devem seguir alterando a biodiversidade e os ecossistemas. A política florestal é uma forte aliada no enfrentamento da perda da biodiversidade e adaptação às alterações climáticas. O quadro composto pelo decréscimo da biodiversidade e a necessidade de sua tutela, em função do avanço dos extremos climáticos, tem sido responsável por uma série de ingerências no direito de propriedade, não só por torná-la mais limitada, sob o ponto de vista do seu uso, mas porque reconfigura cenários de perdas.

\section{Prognósticos do CENÁRIO CIENTÍFICO dAS MUdANÇAS CLIMÁTICAS E OS IMPACTOS NO DIREITO DE PROPRIEDADE}

"A mudança climática é um dos maiores desafios do nosso tempo" (UNFCCC, 2009). Trata-se de fato social altamente relevante para o Direito (REALE, 1982), pois impacta vidas humanas, bens particulares e serviços ambientais, direitos fundamentais para uma vida digna, tais como, saúde, moradia, propriedade, ambiente ecologicamente equilibrado, alimentação, entre outros.

Desde os anos noventa, pesquisadores (IPCC, 2014; CRUTZEN, 2002; CRUTZE, 2006) têm reconhecido e reiterado a parcela de contribuição humana para as mudanças no clima, bem como apontado seus efeitos ao redor do Planeta. De acordo com os estudos, as consequências diferenciar-se-ão em função das características geográficas e o grau de vulnerabilidade de cada região de cada país.

Recentemente, cientistas do Instituto Goddard da NASA para Estudos Espaciais (GISS), em Nova York (GISTEMP) e da Administração Oceânica e Atmosférica Nacional (NOAA) comunicaram que "no ano de 2015 a temperatura da superfície da Terra foi a mais alta desde o início dos registros em 1880". A afirmação teve por base estudos independentes. Considerando algumas questões variáveis como local e tempo, a NASA confirmou a informação com $94 \%$ de certeza (NASA, 2016). O Gráfico 1 demonstra o rápido aquecimento da Terra nas últimas décadas, sendo que na última o mesmo foi recorde.

De acordo com os dados científicos recentes (IPCC, 2013), o aquecimento global médio de 2 graus deixará a terra mais quente do que em milhões de anos. Em alguma medida essa realidade já é inevitável. As consequências futuras previstas abrangem eventos extremos, tais como incêndios, inundações e ondas de calor, que se tornarão mais frequentes e generalizados. Em geral, áreas molhadas devem ficar mais úmidas e áreas secas mais secas. Contudo, se os efeitos do aumento da temperatura em 2 graus são preocupantes, os impactos podem ser muito piores com o provável aumento de até 4 graus, caso as emissões de gases do efeito estufa conti- 
nuem a subir ininterruptamente. Estudo do Banco Mundial (2012) considera esse cenário devastador, com uma lista de consequências, dentre as quais destaca a inundação de cidades costeiras, riscos em relação à produção de alimentos, com potencial aumento dos índices de desnutrição.

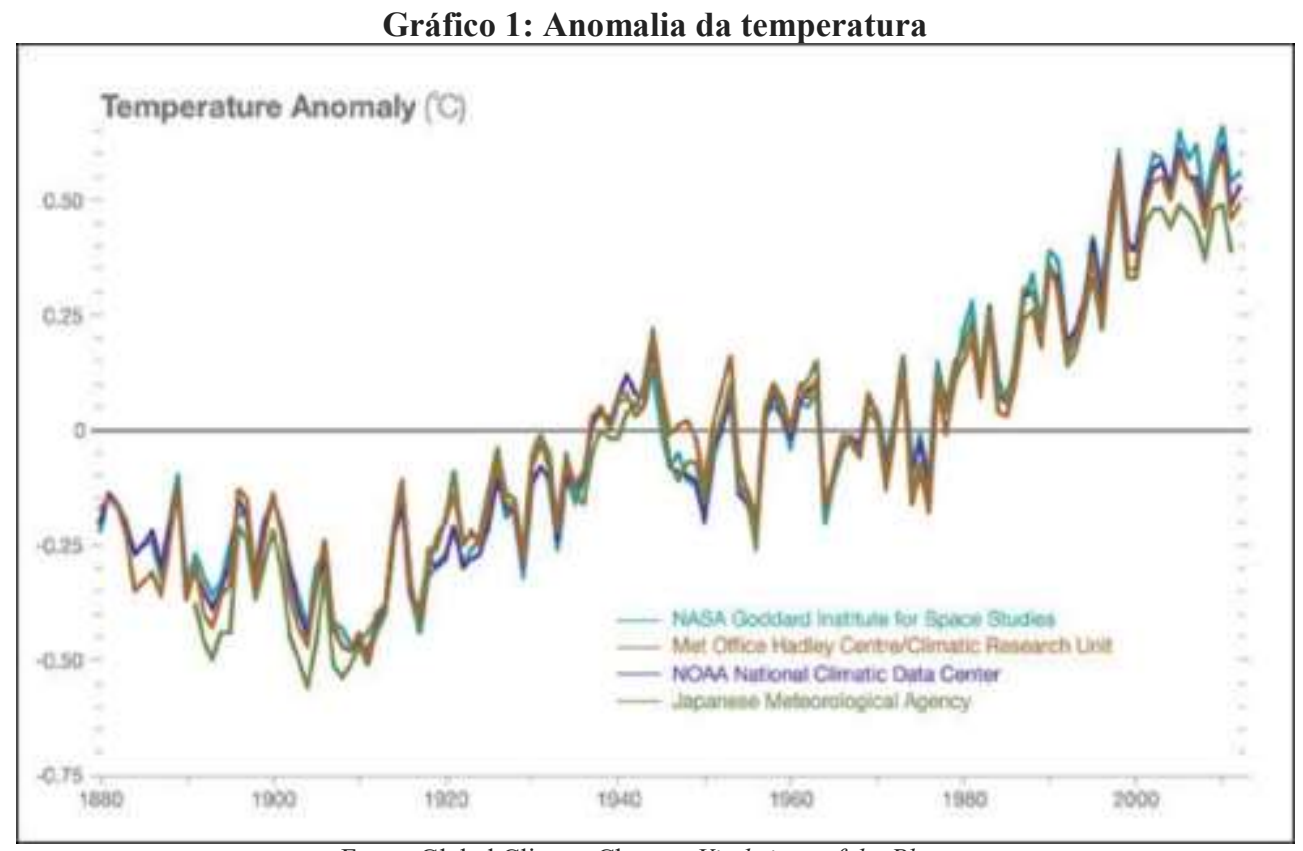

Fonte: Global Climate Change. Vital signs of the Planet.

Disponível em: http://climate.nasa.gov/scientific-consensus/ Acesso em: junho de 2106.

As mudanças físicas e bióticas resultantes da acumulação dos gases causadores do efeito de estufa interromperá as expectativas dos proprietários de imóveis de várias maneiras, entre elas, minando a segurança de seus investimentos e exercendo pressão sobre as definições atuais e distribuições de direitos de propriedade. As áreas costeiras e de água doce vulneráveis ilustram bem essa realidade. (DOREMUS, 2012)

Entre os prováveis danos, direta ou indiretamente causados à propriedade, estão: perdas de propriedades e na pecuária, causadas por inundações, tempestades e incêndios; danos em propriedades nacionais públicas, como parques, áreas nativas e infraestruturas verdes; danos à orla costeira, com a baixa de valores de imóveis; depreciação de rendimentos agrícolas, pecuária e pesca; perda de meios de subsistência e deslocamento de pessoas e bens (SMITH; SHEARMAN, 2006).

Diante dos prognósticos científicos e seu potencial reflexo sobre o direito de propriedade, a questão que se coloca é se em complemento às limitações constitucionais e legais, as transformações esperadas por conta dos efeitos das mudanças climáticas indicam seu "enfraquecimento" (FARBER, 2014). A princípio a resposta é não, mas desde que os movimentos de mudança e adaptação busquem o equilíbrio entre dois direitos fundamentais não absolutos (DANTAS, 2015). As adaptações não podem ser arbitrárias, sectárias ou desproporcionais. Essa cautela, típica de um Estado Democrático de Direito, vale tanto para políticas públicas, quanto para as intervenções do poder judiciário. Nessa linha, as medidas de adaptação impulsionadas pelos reflexos das mudanças climáticas devem, na medida do possível, atender o interesse público, sem desconsiderar o direito de propriedade e institutos correlatos. 
O direito de propriedade e a supremacia do interesse público sobre o privado na era de adaptação às mudanças climáticas

No passado, os dados sobre o clima e as decisões a seu respeito consideravam apenas as flutuações em torno da histórica revelada pela experiência (o passado como orientação para o futuro). Os dados históricos continuam sendo relevantes, mas não são suficientes, pois a hipótese de um mundo natural imutável claramente não coaduna com a realidade de hoje, e está ainda mais distante da realidade do futuro. A visão tradicional de propriedade, cuja característica principal era a estabilidade, foi desenvolvida durante um mundo que ficou para trás (FARBER, 2014). A realidade é, portanto, paradoxal, pois embora o objetivo fundamental do direito de propriedade seja a estabilidade, o Planeta vive uma era em que o clima é instável e causa repercussões conflituosas sobre bens e direitos fundamentais.

Para Farber (2014), diante da mudança climática e sua política atual, o direito de propriedade pode ser tanto parte da solução quanto do problema. Afinal, se por um lado exigirá mudanças na forma como o compreendemos, o que implica grandes dificuldades sociais, sociais e jurídicas; por outro, deve chamar atenção para outros interesses e para novos direitos. Servidões de conservação, transferência de direitos, servidões de energia solar e a alternativa do solo criado são exemplos de institutos que devem ressurgir no debate jurídico por conta dessa nova leitura do direito de propriedade. Esse é um raciocínio otimista, que pode transformar a necessidade de adaptação em uma oportunidade para a tomada de decisões políticas e jurídicas razoáveis e contributivas para a implementação da sustentabilidade como um "novo paradigma para o direito de propriedade" (FERRER et al, p. 1433-1464).

No âmbito da estruturação reflexiva dessa perspectiva, pertinente é a noção de phàrmakon, conceito grego adaptado para o Direito por Elídio Resta (RESTA, 2008, p.86). Trata-se do conceito mais representativo da ambiguidade paradoxal, que é simultaneamente veneno e antídoto, cura e doença, carrasco e vítima, memória e esquecimento, presença e ausência, racionalidade e irracionalidade. Todas as substâncias são venenos, apenas a dose certa diferencia o veneno do remédio. O Direito, da mesma forma, está compreendido entre a oscilação de dois polos da ambivalência. Nesse sentido, sua história é de justas doses a se buscar entre os dois opostos, história jamais concluída, que precisa confiar às vezes na prudência, na racionalidade, na força dos sujeitos em jogo, na técnica normativa e na experiência judiciária.

\section{DA SUPREMACIA DO INTERESSE PÚBLICO SOBRE O PRIVADO: REFLEXÕES RELEVANTES EM UM PROCESSO DE ADAPTAÇÃO}

No Brasil o ambiente é matéria de interesse difuso, o que orienta o uso e fruição da propriedade numa linha de solidariedade coletiva. A partir dessa compreensão, e em complemento com o argumento da função social da propriedade, surge o argumento de que a constitucionalização dos direitos ambientais, conjugada com outras disposições constitucionais relacionadas à propriedade estabelece um quadro que sustenta o argumento de que o interesse público deve prevalecer sobre o privado. A justificativa para tanto é que embora o direito à propriedade figure, expressamente, entre os direitos do artigo $5^{\circ}$, a própria Constituição lhe impõe limitações cruciais, por meio do princípio da função social, sob pena de expropriação. Ao enumerar os critérios para o cumprimento da função social, o artigo 186 da Constituição Federal requer o uso adequado dos recursos naturais disponíveis e preservação do meio ambiente.

Por essa linha de raciocínio, "o direito de propriedade é traçado pelo ordenamento constitucional vigente", mas sua "conotação possa ser tratada pelas normas infraconstitucionais, a par das interpretações jurisprudencial e doutrinária", desde que "não desbordando da moldura constitucional" (FIGUEIREDO, 1980, p.4). Nessa linha, entre os direitos associados à propriedade, não está o poder de transformar o "estado natural" da coisa a ponto de destruí-la. Assim, 
não integra o rol dos atributos do direito de propriedade do dono de uma área pantanosa a possibilidade de, por decisão individual, aterrá-la, modificando seu estado natural e função ecológica (FIGUEIREDO, 1980, p.4).

Em linha de raciocínio semelhante, Benjamin (1996, p. 9-10) destaca que "no Brasil, não há um direito de propriedade que confira ao seu titular a opção de usar aquilo que lhe pertence de modo a violar os princípios hoje estampados nos artigos $5^{\circ}, 170$, inciso VI, 186, inciso II, e 225 , todos da Constituição Federal". A propriedade privada, nos moldes constitucionais" abandona, de vez, sua configuração essencialmente individualista para ingressar em uma nova fase, mais civilizada e comedida, onde se submete a uma ordem pública ambiental." (BENJAMIN, 1996, P. 10)

Na concepção de José Affonso da Silva (2008)' as regras de vizinhança (o limite de um vai até o início do limite do outro) e os deveres coletivos (decorrência das exigências da convivência em sociedade) seriam os exemplos tradicionais de limitações internas ao direito de propriedade. Em complemento a essas limitações surge, no século XX, uma gama de deveres gerais amparados na função social da propriedade. Essas seriam elemento essencial definidor do próprio direito subjetivo, caracterizando-se os deveres daí decorrentes como encargos ínsitos ao próprio direito, orientando e determinando seu exercício, de modo positivo.

A partir dessa perspectiva, os constantes conflitos jurídicos em torno do direito à propriedade e o direito ao ambiente ecologicamente têm cada vez mais recebidos contornos verdes. Considerando um horizonte de futuro de mudanças climáticas, com profundos reflexos tanto no ambiente quanto na propriedade, o fundamento justificador da preponderância de um sobre o merece mais atenta reflexão. No âmbito das limitações administrativas à propriedade e das decisões judiciais que as chancelam, o princípio da supremacia do interesse púbico sobre o privado traz à tona o debate acerca da própria compreensão do princípio, dos deveres e obrigações dos particulares para com a coletividade e as futuras gerações (solidariedade) e, sobretudo, os limites de sua aplicação em em momento delicado de transição e mudanças muito rápidas.

É bastante comum o discurso de que a existência do Estado e suas diversas formas de atuação justificam-se pelo fato de serem os diretos fundamentais a personificação da noção de dignidade da pessoa humana. É também com base nessa justificativa que se pode observar a prevalência das ideias fundantes do chamado regime jurídico administrativo. Uma das noções basilares desse ramo é a do princípio da supremacia do interesse público sobre o privado (SCHIER, 2003, p. 53-57).

Em algumas decisões judiciais, especialmente as que envolvem as relações entre direito fundamental à propriedade e ao meio ambiente ecologicamente equilibrado ${ }^{5}$, a presença

\footnotetext{
5 Um resumo da perspectiva adotada pelo Superior Tribunal de Justiça nesse contexto pode ser explicitado pela noção de que "o direito à integridade do meio ambiente, típico direito de terceira geração, constitui prerrogativa jurídica de titularidade coletiva, refletindo, dentro do processo de afirmação dos direitos humanos, a expressão significativa de um poder atribuído, não ao indivíduo identificado em sua singularidade, mas, num sentido verdadeiramente mais abrangente, à própria coletividade social. Enquanto os direitos de primeira geração (direitos civis e políticos), que compreendem as liberdades clássicas, negativas ou formais, realçam o princípio da liberdade e os direitos de segunda geração (direitos econômicos, sociais e culturais), que se identificam com as liberdades positivas, reais ou concretas acentuam o princípio da igualdade, os direitos de terceira geração, que materializam poderes de titularidade coletiva, atribuídos genericamente a todas as formações sociais, consagram o princípio da solidariedade e constituem um momento importante no processo de desenvolvimento, expansão e reconhecimento dos direitos humanos, caracterizados, enquanto valores fundamentais indisponíveis, pela nota de uma essencial inexauribilidade". Ainda sobre a supremacia do interesse público sobre o privado. BRASIL. Superior Tribunalde Justiça. Resp 1293744. Relator Min: Benedito Gonçalves. Dje: 18 maio 2015. BRASIL. Superior Tribunalde Justiça REsp 977662 /DF. Relator Min: Herman Benjamin. Dje: 01 jun. 2012. BRASIL. Superior Tribunalde Justiça. REsp 1381191 / SP. Min. Diva Malebi. DJe 30 jun. 2016. "A existência da área de reserva legal no âmbito das propriedades rurais caracteriza-se como uma limitação
} 
O direito de propriedade e a supremacia do interesse público sobre o privado na era de adaptação às mudanças climáticas

desse princípio como fundamento de respostas jurisdicionais, em favor do ambiente, já pode ser observada com não tão rara frequência. A ementa a seguir aborda a constitucionalidade do dever de imposição de reserva legal em propriedade. Para a decisão, sua imposição é representativa do argumento de que sob o prisma solidarista e ético em que fundado o ordenamento brasileiro. $\mathrm{Na}$ medida em que o texto constitucional caracteriza o meio ambiente como bem de uso comum do povo e essencial à sadia qualidade de vida, associa-o, como contraface, aos preceitos derivados da dignidade da pessoa humana. Mais que o direito à vida, há de se garantir uma vida digna, em ambiente saudável. Nessa equação, decorrente do dever de proteção ambiental imposto ao Estado, é que se insere a reserva legal, mecanismo destinado à conservação, em áreas de propriedade privada, de fragmentos de florestas e outros tipos de vegetação nativa, contribuindo, portanto, para proteger, ainda que minimamente, a fauna e flora originárias de cada região do país. Nesse sentido:

\begin{abstract}
A normatização do instituto, desse modo, não contém qualquer inconstitucionalidade. A exigência de estabilização das relações sociais não constitui autorização para esvaziamento do dever de proteção ao meio ambiente, porque se trata de núcleo essencial dos direitos fundamentais e chave para a preservação da própria vida humana. No conflito entre estabelecer um prazo prescricional em favor daqueles que não observam as imposições decorrentes da legislação ambiental, a fim de lhes atribuir segurança jurídica e estabilidade, e a necessidade de tutelar de forma concreta bem jurídico coletivo, indisponível, fundamental, que antecede todos os demais direitos - pois sem ele não há vida, nem saúde, nem trabalho, nem lazer este último há de prevalecer. A preservação ambiental constitui razão justificadora do próprio exercício do direito de propriedade. Não se cuida de um mero limite externo, mas da configuração interna do próprio direito. ${ }^{6}$ (grifo nosso)
\end{abstract}

Para Ávila (1999, p. 3), cujo entendimento acerca do princípio diverge dos entendimentos anteriormente mencionados, "a supremacia do interesse público sobre o privado não se identifica com o bem comum, pois o bem comum seria a composição harmônica com o bem de um com o bem de todos; não o direcionamento dessa composição em favor do interesse público." Da forma como vem sendo interpretado, "o referido princípio, representa uma regra de preferência e, a rigor, não pode ser descrito ou conceituado como um princípio jurídico (ÁVILA, 1999, p. 28), tampouco uma norma-princípio" (ÁVILA, 1999, p. 29). Também não pode representar uma relação de supremacia, porque principalmente na relação administrativa, não pode o interesse público, sob o ângulo da atividade administrativa, ser descrito separadamente ou contrapostamente aos interesses privados. Os "interesses privados são parte do interesse público. [...] A supremacia do interesse público só pode ser analisada em uma situação concreta, ao invés de ser um princípio abstrato de supremacia". Nesse sentido, "a única ideia apta a explicar a relação entre interesse público e particular, ou entre o Estado e o cidadão", a ser considerada inclusive pelo poder judiciário, é "o postulado da unidade da reciprocidade de interesses, o qual implica ponderação entre interesses reciprocamente relacionados fundamentada na sistematização constitucional". Assim, seja no que diz respeito "às atividades administrativas e, sobretudo, aquelas que impõem restrições ou obrigações a particulares, a administração não pode exigir um comportamento do particular ou direcionar a interpretação de regras existentes com base neste princípio". (ÁVILA, 1999, p. 29)

Schier (2003) também questiona se a supremacia do interesse público sobre o privado pode consubstanciar um verdadeiro princípio geral do direito público (implicitamente contido na

administrativa necessária à tutela do meio ambiente para as presentes e futuras gerações e se encontra em harmonia com a função ecológica da propriedade, legitimando a existência de restrições aos direitos individuais em benefício dos interesses de toda a coletividade”. BRASIL. Superior Tribunalde Justiça. AREsp 775574. In. Marco Aurélio Bellizze. 29 ago. 2016.

6 BRASIL. Superior Tribunal de Justiça. AREsp 526344. Min. Relator: Ségio Kukina. 31 out. 2014. 
Constituição Federal). Apesar de não abordar o princípio especificamente e, portanto, não analisar seu conteúdo, faz uma crítica à forma ou a pretensão de elevação do interesse público a um patamar hierárquico superior ao ocupado pelos direitos e liberdades individuais. Nesse sentido, "a tese da existência de um princípio da supremacia do interesse público sobre o privado não se sustenta, pois a supremacia do público só se verifica em situações muito específicas e sempre dentro de condições específicas e muito limitadas pela Constituição Federal” (SCHIER, 2003, p. 70). Para o autor, "tem-se olvidado que, ainda quando a referida supremacia se manifesta constitucionalmente, legalmente ou por meio de decisões judiciais, com critério de solução de colisão de interesses ou bens constitucionais, ela não pode ser absoluta, eis que considerada como medida de ponderação" (SCHIER, 2003, p. 70). E, em se tratando de ponderação, não pode haver prévia preferência a um ou outro interesse, de modo que o critério previamente determinados não representa a postura constitucional de tutela de todos os direitos fundamentais. Nesse sentido, o autor alerta para o fato de que a ideia de supremacia do interesse público, erroneamente compreendida como princípio geral do direito público, não pode funcionar como uma cláusula geral de restrição de direitos, liberdade e garantias fundamentais. A partir dessas premissas vislumbra 4 (quatro) situações diferentes. Todas partem na concepção básica de que, em regra, interesses públicos e privados não se encontram em conflito; ao contrário, se completam e harmonizam, pois a realização de um importa na do outro. Nessa linha:

\begin{abstract}
Eventuais colisões serão resolvidas previamente pelo constituinte originário, que pode optar pela prevalência de interesses privados (o que parece ser mais usual) ou pela prevalência do interesse público (como exceção, em homenagem ao princípio da legalidade e do estado de direito). Outras colisões são remetidas ao campo das colisões entre direitos fundamentais, onde o constituinte, expressamente, autoriza, que os direitos, liberdades e garantias individuais cedam, mediante ponderação infraconstitucional (princípio da reserva legal) em favor de interesses públicos, sempre com observância do critério (princípio) da proporcionalidade e respeito do núcleo essencial daqueles (proibição do excesso); Um último grupo de conflitos entre interesses públicos e provados, que não se enquadre em nenhuma situação anterior, deve ter a solução remetida à ponderação, diante do caso concreto, através não da mediação legislativa, mas jurisdicional. (SCHIER, 2003, p. 13)
\end{abstract}

De acordo com a crítica de Binenbojm (2005) ao princípio, “embora decantado pela literatura brasileira como fundamento e princípio normativo do direito administrativo, sua inconsistência teórica e incompatibilidade visceral com a sistemática constitucional dos direitos fundamentais são patentes" (BINENBOJM, 2005, p. 29). Uma orientação que preconiza a supremacia a priori de um valor, princípio ou direito sobre outros não pode ser qualificado como princípio. Logo, "a prevalência, apriorística e descontextualizada, de um princípio constitui uma contradição em termos". "O conceito de interesse público é daqueles ditos juridicamente indeterminados, que só ganham maior concretude a partir da disposição constitucional dos direitos fundamentais em um sistema que contempla e pressupõe restrições ao seu exercício em prol de outros direitos, bem como de metas e aspirações da coletividade de caráter metaindividual" (BINENBOJM, 2005, p. 29-30) igualmente estampadas na Constituição.

Assim:

\begin{abstract}
O melhor interesse público só pode ser obtido a partir de um procedimento racional que envolve a disciplina constitucional de interesses individuais e coletivos específicos, bem como um juízo de ponderação que permita a realização de todos eles na maior extensão possível. O instrumento deste raciocínio ponderativo é o postulado da proporcionalidade (BINENBOJM, 2005, p. 30).
\end{abstract}

Em sentido intermediário, mas questionador das proposições dos autores anteriormente mencionados, Borges (2007, p. 3) argumenta que "todo o direito administrativo está construído sobre dois pilares básicos: a supremacia do interesse público sobre o interesse privado, e a indisponibilidade do interesse público”. Desse modo: 
O direito de propriedade e a supremacia do interesse público sobre o privado na era de adaptação às mudanças climáticas

\begin{abstract}
Não se trata de desconstruir a supremacia do interesse público. Bem ao contrário, na atual conjuntura nacional, o que é preciso, mais do que nunca, é fazer respeitá-la, é integrá-la na defesa dos luminosos objetivos fundamentais de nossa Constituição, expressos em seu monumental artigo 3o. É preciso não confundir a supremacia do interesse público, - alicerce das estruturas democráticas, pilar do regime jurídicoadministrativo, - com as suas manipulações e desvirtuamentos em prol do autoritarismo retrógrado e reacionário de certas autoridades administrativas. O problema, pois, não é do princípio: é, antes, de sua aplicação prática (BORGES, 2007, p. 4).
\end{abstract}

Logo, não há um permanente antagonismo entre interesse individual e interesse público, do qual decorra, necessariamente e sempre, a superioridade deste sobre aquele. Assim, "na medida em que o interesse público e o de um particular, em uma ordem democrática, são qualitativamente iguais e respeitados, quando o interesse individual é alijado ou substituído pela natural predominância do interesse público, tem de ser compensado pela perda de seus direitos e interesses, mediante sua equitativa conversão em outro valor equivalente" (BORGES, 2007, p. 11).

Em complemento às afirmações da autora anteriormente mencionada, cabe o destaque da observação de Eros Grau, para quem "a decisão deve ser definida desde a interpretação da totalidade constitucional, do todo que a Constituição é. Não se interpreta o direito em tiras; não se interpretam textos normativos isoladamente, mas sim o direito, no seu todo". A "ponderação entre princípios se dá no momento da formulação da norma de decisão, não no quadro anterior, de produção das normas jurídicas resultantes da interpretação" (GRAU, 2009, p.16-19).

Santos (2007, p.25), por sua vez, defende não haver, propriamente, um caso de colisão de direitos quando se coteja o direito de propriedade definido na Constituição com o direito a um meio ambiente ecologicamente equilibrado. Logo:

\begin{abstract}
Ao se delimitar o âmbito normativo do direito de propriedade, que dá a real dimensão de sua aplicabilidade, verifica-se que este não abrange condutas contrárias à preservação de um meio ambiente ecologicamente equilibrado. Em razão da existência, na Constituição, da consagração de um conjunto de regras e de princípios que, de per se, já se apresentam como redutoras do alcance da definição de propriedade, como o dever à submissão ao cumprimento de uma função social, a delimitação do âmbito da norma, ou seja, a definição do seu alcance, demonstrará o direito de propriedade como um direito limitado.
\end{abstract}

Ainda, de acordo com o autor, também não parece razoável:

Um jus subietionis instituidor de um dever de suportar o proprietário, sem reparação pecuniária, uma redução absoluta ao exercício das faculdades inerentes à ideia de propriedade, que venha a anular, na prática, tal direito. No caso concreto é que será possível aferir se está sendo imposta uma limitação compatível com o exercício do direito de propriedade ou se sofre o titular daquele direito uma excessivamente onerosa imposição. Caso se verifique a redução próxima à anulação prática do próprio instituto da propriedade, os ônus devem ser repartidos por toda a sociedade, com a instituição de um dever de indenizar a ser suportado pelo poder público (SANTOS, 2007, p.25).

De acordo com os argumentos apresentados ao longo desta breve exposição, observa-se a possibilidade do desenvolvimento de um argumento intermediário, cujo ponto principal seja busca do equilíbrio entre o melhor para a manutenção e, quando necessário, recuperação do ambiente, mas sem o exaurimento ou desconsideração de outros direitos fundamentais que com ele se relacionem. Não existem direitos absolutos. O direito de propriedade serve para garantir direitos individuais contra interferência do poder público e de outros indivíduos, como também para assegurar direitos públicos de acesso e fruição dos bens públicos. As normas ambientais, por seu tuno, são concebidas para proteger o sentido jurídico mais amplos do ambiente, o que inclui a natureza, os elementos culturais, patrimoniais, do trabalho e os interesses públicos associados. Por exemplo, um sistema de responsabilidade por danos ambientais protege o interesse 
público contra a socialização dos custos privados para a saúde humana e ambiental. Assim, é bastante comum que o direito ambiental, na regulação do gozo dos direitos ambientais, gere alguma situação de ingerência e conflito com o direito de propriedade. Quando esse conflito surge, é fundamental que o Direito desenvolva o papel de equilibrar os interesses públicos e privados, de modo a atingir os objetivos sociais coletivos, tendo em consideração as demandas atuais por desenvolvimento, sustentabilidade e adaptação às mudanças climáticas, sem comprometer ou desconsiderar outros direitos também fundamentais. Por essa razão, parece proporcional e razoável compreender que "a necessidade de adaptação às mudanças climáticas não deve propiciar decisões judiciais e políticas que favoreçam o enfraquecimento de institutos importantes como a segurança patrimonial e jurídica" (FARBER, 2014, p. 11-13).

A mudança climática é um problema social especialmente difícil para o direito de propriedade que, tradicionalmente, absorve mudanças de forma contínua e paulatina, e agora choca-se com um ambiente em rápida mutação, que exige agilidade. Se a agilidade é uma necessidade complexa para o Direito em geral, mais difícil é para o de propriedade, cuja natureza intrínseca prioriza o favorecimento da estabilidade ao longo do tempo. Por isso, não raramente o direito de propriedade visto "como uma área em que o ritmo da mudança é glacial, contudo é bom lembrar que, nos dias atuais, mesmo geleiras estão se movendo com velocidade sem precedentes" (FARBER, 2014, p.32).

A partir dessa realidade, e com vistas a potencializar as chances de uma adaptação bemsucedida, faz sentido refletir sobre como essa necessária transição precisa ser planejada e executada com vista a considerar, ponderadamente, todos os direitos envolvidos. Esse planejamento envolve um processo de governança (envolvimento de diversos atores), normatização (com ex. ambiental, urbanística), decisão (política, administrativa e orçamentária) e de gestão de riscos em uma escala e grau complexidade jamais enfrentados pela humanidade e, consequentemente pelo Direito. É exatamente pelo traço inusitado e incerto que tem a mudança climática, que as reflexões acerca de direitos e institutos fortemente impactados por ela devem começar agora.

\section{CONSIDERAÇÕES FINAIS}

No Brasil, a expressão "meio ambiente ecologicamente equilibrado" é representativa tanto de direito, quanto de dever, em decorrência da importância do bem tutelado. Essa interpretação decorre da leitura da Constituição Federal e das orientações direcionadas ao poder público e à coletividade (proprietário), com vistas à preservar as condições de uma vida digna para a presente e futuras gerações. A orientação de solidariedade intergeracional impressa no dever constitucional ganha uma relevância jamais imaginada diante de um provável cenário de escassez e perdas ecossistêmicas desencadeadas pela mudança climática.

Nessa linha de raciocínio, doutrina e tribunais desempenham papéis fundamentais na interpretação/aplicação da Constituição e da legislação, o que muitas vezes implica imputação de responsabilidades e deveres públicos e privados. Considerando que os direitos correlatos ao ambiente são essenciais para ordem pública e individual, as decisões falam por si e estabelecem uma tendência de aplicação mais rigorosa da legislação ambiental no Brasil, sobretudo em relação à propriedade. O limite entre o exercício de um ou outro direito é objeto de boa parte dos conflitos em matéria ambiental na atualidade. A constitucionalização dos direitos e deveres ambientais forneceu um quadro que tem ampliado o sentido da função ambiental da propriedade, enfatizando o bem público associado à proteção do meio ambiente, e elevando o interesse público sobre o privado em casos de intersecção do ambiente com a propriedade privada. O debate relevante nesses casos é exatamente o fundamento das decisões e seus critérios, ou a falta deles. 
O direito de propriedade e a supremacia do interesse público sobre o privado na era de adaptação às mudanças climáticas

Ademais, a evolução interpretativa é uma das características do Direito, processo interativo que funciona pela tensão entre determinismo e adaptabilidade. Embora sua sistematicidade e ordenação sejam desejáveis, nenhum sistema legal é completo e imutável. Nesse sentido, regras e princípios devem ser constantemente testados e expostos à crítica e controle mediante debate público, desafios e necessidade sociais.

A mudança climática é um dos maiores desafios do nosso tempo. Trata-se de fato social altamente relevante para o Direito, pois impacta vidas humanas, bens particulares, serviços ambientais, diversos ramos do Direito e direitos fundamentais. No campo do Direito Civil, por exemplo, o direito de propriedade possui relação direta com o aumento ou a redução da vulnerabilidade. Se por um lado o uso impróprio da propriedade pode ser o desencadeador de vulnerabilidades físicas e sociais; por outro, a crescente variabilidade climática e o aumento de eventos extremos pode expô-la a vulnerabilidades até então desconhecidas. É importante lembrar que a perda da terra pode representar, também, a perda de meios de subsistência e habitação; perda da identidade espiritual de uma cultura ou, ainda, causar o deslocamento de comunidades. Assim, a maneira com um sistema jurídico trata as questões envolvendo a propriedade, redundará em maior ou menor vulnerabilidade desse Direito, particularmente em tempos de mudança climática.

Essa não é uma tarefa simples ou de soluções prontas. Ao contrário, o processo de adaptação da propriedade às mudanças climáticas tende a ser longo e controvertido. A complexidade sobressalente à abordagem da conhecida tensão entre os direitos fundamentais — meio ambiente ecologicamente equilibrado e propriedade — não é novidade, mas ganha contornos imaginados diante do fenômeno climático. Nesse sentido, se por um lado adaptar-se é necessário, por outro, uma interpretação sistêmica, razoável e condizente com a Constituição, fundamenta-se em critérios capazes de seguir tutelando deveres fundamentais de solidariedade, a partir de sua interpretação abrangente. O interesse privado é a outra face da moeda do interesse público. Ademais, já é tempo de compreender que ambiente e propriedade não estão em lados opostos. Essa visão é muitas vezes uma forma de induzir comportamentos de menor proteção do que se deseja em relação ao ambiente.

Nesse sentido, a necessidade de adaptação jurídica, política e econômica à mudança climática deve priorizar ações e decisões que harmonizem a necessária proteção ambiental com institutos também altamente relevantes para um Estado Democrático de Direito, como a propriedade, segurança patrimonial, jurídica, compensação, entre outros.

\section{REFERÊNCIAS}

ÁVILA, Humberto. Repensando o princípio da supremacia do interesse público sobre o particular. Revista trimestral de direito público, v. 24, p. 159-180, 1999.

BENJAMIN, Antonio Herman de Vasconcellos. Direito de propriedade e meio ambiente. 1996. Disponível em: <http://bdjur.stj.jus.br/dspace/handle/2011/34591>. Acesso em: junho de 2016

BINENBOJM, Gustavo. Da supremacia do interesse público ao dever de proporcionalidade: um novo paradigma para o direito administrativo. Revista de Direito Administrativo, v. 239, 2005.

Da Supremacia do Interesse Público ao

dever de proporcionalidade: um novo paradigma para o direito administrativo. In: SARMENTO, Daniel (Org.). Interesses Públicos versus Interesses Privados: desconstruindo o princípio de supremacia do interesse público. Rio de Janeiro: Lúmen Júris, 2005, p. 117-171. 
BRASIL. Superior Tribunal de Justiça. Resp 1293744. Relator Min: Benedito Gonçalves. DJe 18 maio 2015.

REsp 977662 /DF. Relator Min: Herman Benjamin. DJe 01 jun. 2012. REsp 1381191 / SP. Min. Diva Malebi. DJe 30 jun. 2016. AREsp 775574. In. Marco Aurélio Bellizze. 29 ago. 2016.

CARVAlHO, Délton Winter de. Dano Ambiental Futuro: a responsabilização civil pelo risco ambiental. 2 ed. Porto Alegre: Livraria do Advogado, 2013.

CRUTZEN, Paul J. Geology of mankind. Nature, v. 415, n. 6867, p. 23-23, 2002.

. The "anthropocene". In: Earth system science in the anthropocene. Springer Berlin Heidelberg, 2006. p. 13-18. Disponível em: http://mfkp.org/INRMM/article/13558644. Acesso em: jun. 2015.

DANTAS, Marcelo B. Direito ambiental de conflitos. Rio de Janeiro: Lumens Juris, 2015.

DI PIETRO, Maria Sylvia Zanella. Direito administrativo. São Paulo: Atlas, 2005. p. 109.

FARBER, Daniel A. Property Rights and Climate Change, 2014. Disponível em: $<$ http://ssrn.com/abstract=2418756>. Acesso em: mar. 2015.

. Separated at Birth? Addressing the Twin Global Crises of Biodiversity and Climate Change. UC Berkeley Public Law Research Paper, n. 2593498, 2015. Disponível em: $<$ http://papers.ssrn.com/sol3/papers.cfm?abstract_id=2593498>. Acesso em: jun. 2015.

FIGUEIREDO, Lúcia Valle. Disciplina Urbanística da Propriedade. São Paulo: RT, 1980.

FREITAS, Vladimir Passos de. A Constituição Federal e a efetividade das normas ambientais. Revista CEJ, v. 4, n. 10, p. 114-118, 2008.

FREITAS, Juarez. Sustentabilidade: Direito ao Futuro. Belo Horizonte: Fórum, 2011.

FERRER, Gabriel Real Ferrer Real; GLASENAPP, Maikon Cristiano; CRUZ, Paulo Márcio. Sustentabilidade: um novo paradigma para o direito. Novos Estudos Jurídicos, v. 19, n. 4, p. 1433-1464, 2014.

GRAU, Eros Roberto. A Ordem Econômica na Constituição de 1988: interpretação e crítica. São Paulo: Malheiros, 2004.

$\overline{19,2009}$

O perigoso artifício da ponderação entre princípios. Justiça e Cidadania, n. 108, p. 16-

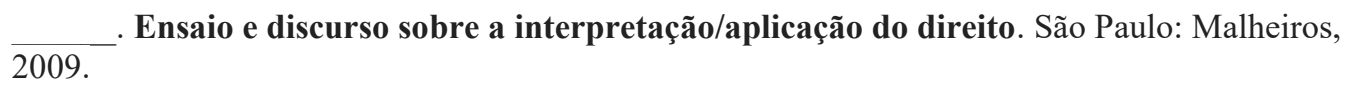

HEINEN, Juliano. Limitações administrativas e o conteúdo econômico da propriedade: uma "desapropriação à brasileira”. Revista de Direito Administrativo, v. 260, p. 167-181, 2012.

IPCC. Summary for Policymakers in Climate Change 2013: The Physical Science Basis. Contribution of Working Group I to the fifth assessment report of the Intergovernamental panel on climate change 5. 2013. Disponível em: $<$ http://www.climatechange2013.org/>. Acesso em: jun. 2015.

. Climate Change 2014. Impacts, Adaptation and Vulnerability: Regional Aspects. Cambridge University, 2014. 
O direito de propriedade e a supremacia do interesse público sobre o privado na era de adaptação às mudanças climáticas

MEIRELLES, Hely Lopes. Direito Administrativo Brasileiro. São Paulo: Malheiros, 2006.

MELLO, Celso Antônio Bandeira de. Curso de Direito Administrativo. São Paulo: Malheiros, 1997.

MILARÉ, Édis. Princípios fundamentais do direito do ambiente. Revista dos Tribunais, v. 756, p. 53, 1998.

NABAIS, José Casalta. O dever fundamental de pagar impostos: contributo para a compreensão constitucional do Estado fiscal contemporâneo. Coimbra: Almedina, 2009.

REALE, Miguel. Lições preliminares de direito. Coimbra: Almedina, 1982.

SAX, Joseph L. Property rights and the economy of nature: Understanding Lucas v. South Carolina Coastal Council. Stanford Law Review, p. 1433-1455, 1993.

SCHIER, Paulo Ricardo. Ensaio sobre a supremacia do interesse público sobre o privado e o regramento jurídico dos direitos fundamentais. Revista Unibrasil - Cadernos da escola de direito e relações internacionais, v.1, n.2, 2003.

SILVA, José Afonso da. Direito urbanístico brasileiro. São Paulo: Malheiros, 2008.

SÉ, João Sento. Desapropriações anômalas. Revista de Direito Administrativo, v. 152, p. 27 44, 1983.

SMITH, Joseph; SHEARMAN, David. Climate Change Litigation. Analysing the law, scientific evidence \& impacts on the environment, health and property. Presidian: Adelaide, 2006.

THE WORLD BANK. Turn Down the Heat: Why a $4^{\circ} \mathrm{C}$ Warmer World Must be Avoided, 2012. Disponível em: <http://www.worldbank.org/en/topic/climatechange/publication/turndown-the-heat-climate-extremesregional-impacts-resilience>. Acesso em: jun. 2015.

WEISS, Edith Brown. In fairness to future generations. Environment: Science and Policy for Sustainable Development, v. 32, n. 3, p. 6-31, 1990.

UNFCCC. The Copenhagen Accord, FCCC/CP/2009/11/Add.1. United Nations Framework. 